\title{
Cutaneous polyarteritis nodosa
}

INSERM

\section{Source}

INSERM. (1999). Orphanet: an online rare disease and orphan drug data base. Cutaneous polyarteritis nodosa. ORPHA:439729

Cutaneous polyarteritis nodosa (CPAN) is a rare limited form of polyarteritis nodosa (PAN, see this term), characterized by cutaneous vasculitis and mild and transient extracutaneous manifestations such as mild arthralgia, arthritis,myalgia, and rarely peripheral neuropathy. 